\title{
Scientists look to Saudi Arabia for coronavirus clues
}

\author{
The country has had the most infections so far, but has released little information.
}

\section{David Cyranoski}

17 May 2013

Saudi Arabia has become the focus of efforts to understand a novel human coronavirus after the emergence of a large cluster of cases in the country. So far, however, Saudi officials have shared little information.

The Middle East respiratory syndrome coronavirus (MERS-CoV, previously known as hCoV-EMC) causes severe pneumonia and often death. Since the beginning of May, Saudi Arabia has confirmed 21 infections, resulting in 9 deaths. These account for more than half of the 40 cases, including 20 deaths, that have been reported worldwide since September 2012. Most of the cases in the current cluster are related to a single health facility.

The latest outbreak in Saudi Arabia provides further evidence of limited human-tohuman transmission. In all clusters so far, any human-to-human spread has required close contact, and there remains no evidence of sustained spread in the community.

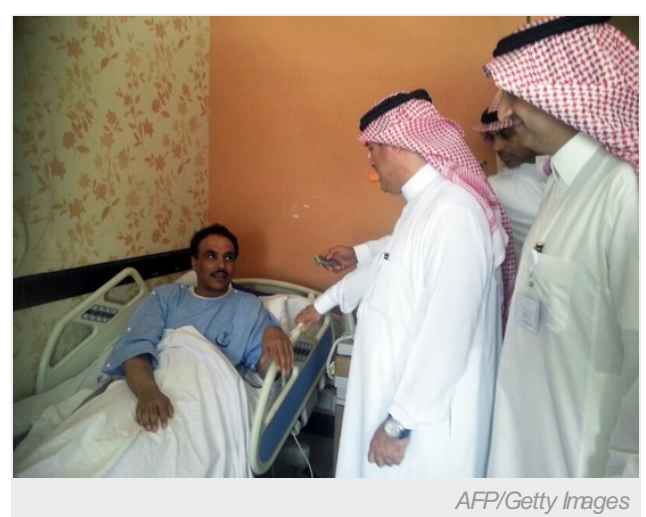

A Saudi health ministry official visits patients infected with a new SARS-like virus at a hospital in the eastern Saudi province of al-Ahsaa on 13 May.

One focus of attention was a haemodialysis unit at the hospital that may have been related to the latest cluster. Peter Horby, an epidemiologist at the Oxford University Clinical Research Unit in Hanoi, thinks that a more likely scenario is that transmission is occurring through various medical procedures, such as tracheal intubations or bronchoscopies, both of which are performed on people with respiratory distress.

\section{More data}

But researchers are still waiting for information that could help them to understand the virus, such as genetic sequences from a large number of cases. Five sequences have been posted and have been crucial in identifying the receptor that the virus uses to infect human cells. But to the frustration of researchers, only one of those sequences came from Saudi Arabia - even though the country accounts for more than half of reported cases.

More might be coming soon."We are working on sequencing of the virus from the recent cluster," says Ziad A Memish, Deputy Minister for Public Health and Director WHO Collaborating Center for Mass Gathering Medicine. "We expect this work will be completed in the next 2-3 weeks." Asked whether the sequences would be shared with researchers, Memish said: "Investigation is ongoing and the [health ministry] will summarize findings and possibilities soon."

"It is of the utmost importance to obtain further detailed sequence data of the viruses that caused the recent outbreak," says Bart Haagmans, a virologist at the Erasmus Medical Center in Rotterdam, the Netherlands. Such data would help researchers not only to further understand the epidemiology of this virus, but also to investigate whether antivirals and any candidate vaccines will also work against it, he adds.

Another key tool will come from serology tests — which detect antibodies to the virus in plasma and serum — that are now under development in countries including the United States and the United Kingdom. But the most immediate benefits will come from data from Saudi Arabia — when they are released, says McCloskey.

\section{Finding the source}

The coronavirus, like its close relative SARS (severe acute respiratory syndrome), is thought to be jumping to humans from one or more animal hosts, or reservoirs. The MERS-CoV host is currently unknown, but the virus is genetically closest to bat coronaviruses.

The spate of clusters in hospitals has evoked comparisons with SARS, which sickened many health workers, killing some. The novel coronavirus is not transmitted so easily and, as a result, the number of cases is smaller. But that could just reflect an earlier stage in 
the evolution of the disease.

Nature | doi:10.1038/nature.2013.13000 